\title{
RETRACTED ARTICLE: Application of machine learning (ML) and internet of things (IOT) in healthcare to predict and tackle pandemic situation
}

\section{R. Sitharthan ${ }^{1} \cdot$ M. Rajesh ${ }^{2}$}

Accepted: 30 July 2021 / Published online: 7 August 2021

(c) The Author(s), under exclusive licence to Springer Science+Business Media, LLC, part of Springer Nature 2021

The Editor-in-Chief and the publisher have retracted this article. The article was submitted to be part of a guest-edited issue. An investigation by the publisher found a number of articles, including this one, with a number of concerns, including but not limited to compromised editorial handling and peer review process, inappropriate or irrelevant references or not being in scope of the journal or guest-edited issue. Based on the investigation's findings the Editor-in-Chief therefore no longer has confidence in the results and conclusions of this article.

Author R. Sithartan disagrees with this retraction. Author M. Rajesh has not responded to correspondence regarding this retraction.

The online version of this article contains the full text of the retracted article as Supplementary Information.

Supplementary Information The online version contains supplementary material available at https://oi. org/10.1007/s10619-021-07358-7.

R. Sitharthan

sitharthan.r@vit.ac.in

M. Rajesh

csemanoharanrajesh@gmail.com

1 Department of Electrical Engineering, School of Electrical Engineering, Vellore Institute of Technology and Science, 632014 Vellore, India

2 Sanjivani College of Engineering, Kopargaon, \& RaGa Academic Solutions, Chennai, India 